\title{
Nefes Terapisinin Genel Sağlık ve Kadın Sağlığı Üzerine Etkileri
}

\author{
Ebru Yalçın ${ }^{\mathrm{a} 1, *}$, Ferda Özbaşaran ${ }^{\mathrm{b} 2}$ \\ a İstanbul Sabahattin Zaim Üniversitesi, Lisansüstü Eğitim Enstitüsü, Kadın Să̆lığı ve Hastalıkları Hemşireliği Programı, İstanbul, Türkiye \\ b ístanbul Sabahattin Zaim Üniversitesi, Sağlık Bilimleri Fakültesi, Hemşirelik Bölümü, İstanbul, Türkiye
}

İstanbul Sabahattin Zaim Üniversitesi Fen Bilimleri Enstitüsü Dergisi (2021) 3 (2): 106-111

https://doi.org/10.47769/izufbed.866042

(iD) ORCID ${ }_{1}^{1}$ 0000-0001-7224-9591; ${ }^{2}$ 0000-0001-7125-9704

\begin{tabular}{l} 
YAYIN BİLGİSİ \\
\hline Yayın geçmişi: \\
Gönderilen tarih: 21 Ocak 2021 \\
Kabul tarihi: 07 Şubat 2021 \\
\\
Anahtar kelimeler: \\
Kadın sağlığı \\
Nefes Terapisi \\
Hemşirelik \\
Sağlık
\end{tabular}

\begin{abstract}
ÖZET
Batı tıbbındaki tedavilerin çoğu genel, tamamlayıcı ve alternatif tıp olarak ifade edilmektedir. Amerika Birleşik Devletleri Ulusal Sağllk Enstitüsü bu yöntemleri "doğal ürünler" ve "bedenzihin uygulamaları" olarak iki temel gruba ayırmıştır. Bu kapsamda nefes terapisi bir beden-zihin uygulamasıdır. Günümüzde insanlar hastalıkların tedavisinde ve/veya semptomlarının yönetiminde olumlu etkilerinden dolayı nefes tekniklerini öğrenme girişiminde bulunmaktadır. Geçmişten günümüze nefes terapisinin iyileştirici etkilerinin çok sınırlı kanıtları olmasına rağmen kadın sağlığı ve nefes terapisi üzerine literatürde yer alan bilimsel çalışmaların son on yılda arttı̆̆ görülmektedir. Bu derlemenin amacı, nefes terapisinin genel sağlık ve kadın sağlı̆̆ı üzerindeki kullanım alanları ve etkilerini tespit etmek alanda yapılan çalışmaları inceleyerek, bu çalışmaların ülkemiz sağlıklılık tanımlamasında edineceği yeri tartışmaktır.
\end{abstract}

\section{Effects of Breath Therapy on General Health and Women's Health}

\begin{tabular}{l}
\hline ARTICLE INFO \\
\hline Article history: \\
Received: 21 January 2021 \\
Accepted: 07 February 2021 \\
Key words: \\
Women's health \\
Breathing Therapy \\
Nursing \\
Health
\end{tabular}

\begin{tabular}{l}
\hline ABSTRACT \\
Most treatments in Western medicine are referred to as general, complementary and alternative \\
medicine. The United States National Institute of Health divided these methods into two basic \\
groups as "natural products" and "body-mind applications". In this context, breathing therapy is \\
a body-mind application. Today, people attempt to learn breathing techniques because of their \\
positive effects in the treatment of diseases and / or the management of their symptoms. Although \\
there is very limited evidence of the healing effects of breath therapy from past to present, it is \\
seen that scientific studies in the literature on women's health and breathing therapy have \\
increased in the last decade. The purpose of this review is to determine the areas of use and effects \\
of breathing therapy on general health and women's health and to discuss the place these studies \\
will gain in the definition of health in our country by examining the studies conducted in the field.
\end{tabular}

\section{Giriş}

Son dönemlerde sağlıklı olan bireylerin sağlıklarını koruma ve geliştirme, sağlık sorunu yaşayan bireylerin ise sağlıklarını yeniden kazanmak için geçmişe göre daha çok Tamamlayıcı ve Alternatif Tedavi (TAT) uygulamalarına yöneldikleri görülmektedir (Aktaş B. 2017). 'Ülkemizde Tamamlayıcı ve Alternatif Tedavi Uygulamaları Yönetmeliği, 27 Ekim 2014 tarihinde 29158 sayı ile Resmi Gazetede yayımlanarak yürürlüğe girmiştir' (www.resmigazete.gov.tr). Bilimsel tedaviler dışındaki tedavilerin çoğu genel, tamamlayıcı ve alternatif tıp olarak ifade edilmektedir. Amerika Birleşik Devletleri Ulusal Sağlık Enstitüsü bu yöntemleri “doğal ürünler" ve "beden - zihin uygulamaları" olarak iki temel gruba ayırmıştır. Bu kapsamda nefes terapisi bir beden zihin uygulamasıdır. Bazı kaynaklarda nefes terapisi bazılarında ise nefes egzersizi ya da solunum egzersizi olarak yer almaktadır. Günümüzde insanlar hastalıkların tedavisinde veya semptomların yönetiminde olumlu etkilerinden dolayı nefes teknikleri eğitimine rağbet etmiştir.

Geçmişten günümüze nefes terapisinin iyileştirici etkilerinin 
çok sınırlı kanıtları olmasına rağmen kadın sağlığı ve nefes terapisi üzerine litaratürde yer alan bilimsel çalışmaların son

on yılda arttığı görülmektedir. Sağlık hizmetleri sisteminin bir parçası olan hemşire ve sağlık çalışanlarının, sağlığına kavuşmak ya da sağlığını korumak amacı ile TAT yöntemlerini kullanan bireylerin kullandıkları yöntemin doğru şekilde değerlendirmelidir. Seçtikleri yöntemin amaçlarının, sonuçlarının ya da risklerinin doğru bir şekilde aktarılmasında çok önemli görevler düşmektedir (Aktaş B. 2017). Solunumun fizyolojik mekanizması, merkezi sinir sistemi tarafindan tetiklenen bir savaş ya da kaç refleksi olduğu için koruyucu bir eylemdir. Almancada "Atem" kelimesi "Nefes", "Atmen" kelimesi de "Nefes Almak" anlamına gelir. 5000 yıllık kadim bir lisan olan Sanskritçede bulunan "Atman" kelimesi çok önemlidir ve bu kelimenin Türkçesi "Can", İngilizce tam karşılığ1 ise "Soul” dur. Yine İngilizcede bir kişi zihinsel olarak çok enerjik ve yaratıcı ise onun için de "Inspired" ifadesi kullanılır. Diğer bir anlamı soluk almak olan inspire kelimesi, ilham vermek anlamında da kullanılır. Nefes almak kelimesinin karşılıkları Fransızcada "Respirer", İtalyancada "Respirare", Flemekçede "Ademen", Almancada "Atmen" fiilleriyle ifade edilir ve Sanskritçedeki "Ruh" ve "Can" 1 ifade eden kelimeden türetildiği görülmektedir. Nefes, nefes almak, nefes vermek kelimeleri birçok lisanda yaşamak için direkt ihtiyaç duyulan en temel enerji, yaşam enerjisi ve yaratıcılık ile özdeşleşmiştir ve bu mana soluduğumuz havanın da ötesinde bir anlam taşımaktadır (Şinik E, 2019). Fizyolojik olarak derin karın nefesi parasempatik sinir sistemini uyarır (Baljon, K. et al.2020). Nefes, yaşantımızın her alanında bize refakat eden ve kaliteli yaşam için sağlıklı bir şekilde hayatta kalmamızı sağlayan birincil aktivitemizdir (Acar N, 2016). WHO (Dünya Sağlık Örgütü) nefesi aldığımız havayı (oksijeni) akciğerlere tam olarak doldurmak ve nefes alışverişi esnasında diyafram kasını kullanmak olarak tanımlamaktadır. Nefes, dahili hava dolaşımı denilen iki aşamadan oluşur. Bu aşamalar soluk alma ve soluk vermedir. Bir insan saatte 3 bin $600 \mathrm{kez}$ nefes alır. Böylece bir insan 1 günde ortalama $86400 \mathrm{kez}$ nefes alır. İyi yaş alma (well-aging) sürecinin en basit ve en etkili yollarından biri de doğru ve bilinçli nefes almaktır (Şinik E, 2019). Solunum ve nefes arasındaki farklılık; nefes bir miktar odaklanma gerektirirken, solunumu sürdürmek için dikkat gerektirmez (Novotny $\mathrm{S}$, et al.2013). Solunum reflekstir, nefes alma ise davranışsaldır (Peter M, 2016).

Nefes terapisinin bilinen tarihine baktığımızda nefes tekniklerinin iyileştirici gücü, insanlık tarihinin başından beri en önemli tedavi yöntemi olmuştur. Nefes teknikleri ile bilinci etkilemenin ve fiziksel iyileşme sağlamanın mümkün olduğu bilindiği için kadim zamanlardan günümüze dek süregelmiş spiritüel ve mistik gelenekte, nefesin ani şekillerle tetiklenmesi ile bilinç açılımları oluşturulmaya çalışılmıştır. Bir zamanlar spiritüel topluluklara katılmak isteyenlerden uzunca bir süre suyun altında kalmaları istenirdi. Yine bu kabullerde kişiler yoğun dumanda bırakılarak uzunca bir süre nefesini tutmaya ve nefessiz kalmaya zorlanırdı. Bu yöntemler doğunun Hint nefes bilimi pranayamada oldukça geliştirilmiş teknikler olarak anlam kazandı. Nefesin Hint kültüründe gelişimi yoga, meditasyon ve konsantrasyon teknikleri olarak şekil ald1. (Kartal M, 2018). Bireylerin proaktif sağlık yaklaşımları özellikle bazı rahatsızlıklar için nispeten yetersiz veya etkisiz tıbbi uygulamaların varoluşu ve ömrün olabildiğince uzun bölümünü olabildiğince sağlıklı geçirebilme arzusu konvansiyonel tıbbi yaklaşımlar yanında farklı arayışları tetiklemektedir (Demirağ S, 2019).

Nefes terapisinde kullanılan bazı terimler vardır. Bunlar;

1. Pranayama

İstemli nefes kontrolü uygulaması; hızlı veya yavaş bir şekilde gerçekleştirilebilen nefes alma, nefes tutma ve nefes verme anlamına gelir. Nefes hareketinin manipülasyonu olarak tanımlanan pranayamik solunumun, düşük oksijen tüketimi, düşük kalp atım hızı ve düşük kan basıncının yanı sıra EEG kayıtlarında artan teta dalgası varlığı ile karakterize fizyolojik bir tepkiye katkıda bulunduğu gösterilmiştir (Jerath $\mathrm{R}$ et al.2006). Pranayama olarak ifade edilen nefes teknikleri; akciğerin üst, orta ve alt bölümlerinin kullanıldığı bilinçli nefesler, aralıklı (interval) nefesler (inhalasyon ve ekshalasyon süresinin değiştiği), burun deliklerinden ve karından alınan nefesler şeklinde değişik varyasyonlarda uygulanmaktadır. Pranayama gibi solunum egzersizlerinin uygulanmasının, sempatik veya parasempatik aktiviteyi değiştirerek otonomik fonksiyonu iyileştirdiği bilinmektedir (Şinik E, 2019).

Nefes teknikleri, rahatlama, stres yönetimi, psiko-fizyolojik durumların kontrolü ve organ fonksiyonunun iyileştirilmesi için düzenli olarak uygulanmaktadır (Ritz T, Roth WT, 2003). Aslında nefes tekniklerinin amacının çoğu, otonom sinir sistemini sempatik baskınlığından uzaklaştırmaktır.

\section{Holoterapi}

Yunanca holos (bütünlük) ve terapi (bakmak,tedavi etmek) kelimelerinin birleşmesinden oluşarak bütüncül bakı/tedavi anlamında kullanılmıştır. Holoterapi çalışmalarında genellikle aborginal teknikler veya kutsal kabul edilen ritüeller yoluyla olağanüstü bilinç durumları meydana getirilir. Bu teknikleri uygulama sırasında çeşitli davul, zil ve gonklar çalınabilir, ilahiler söylenebilir, ritmik danslar ile nefes yöntemleri kullanılabilir böylece bilinçaltının tetiklenmesi amaçlanır. Holoterapi hallerinin oluşturulması şamanizm geçiş törenleri ve yerli kültürlerin diğer ayinlerinin odak noktası olmuştur.

Son yüzyılda batılı terapistler hızlı solumanın iyileştirici potansiyellerini yeniden keşfederek yeni teknikler oluşturdular. Bu sayede Hint ve Tibet nefes uygulamalarıyla modern bilimin ortaya çıkardığı araştırma sonuçlarını harmanlayarak yeni teknikler ortaya çıkardılar. 1960'larda Dr.Stanislav Grof, eşi Cristina Grof ile birlikte Çekoslovakya'nın Prag şehrinde Psikiyatri Araştırmalar Enstitüsünde olağandışı şuur hallerini araştırarak başlattıkları çalışmalarına,1995'lerde Holotropik terapi adlı bir nefes tekniği eklediler (Kartal M, 2018).

\section{İyileştiren Nefes ve Nefes Çeşitleri}

Solunum mekanizmamız doğarken geçirdiğimiz solunum travmasının bir sonucu olarak şifaya ihtiyaç duyar. İlk nefesimiz siviyla dolu, acitıcı ve sirtımıza vurulmasının bir sonucuydu. Hayatta her ne zaman zor anlar yaşasak nefesimizi tutma eğilimi gösteririz. Bu da tüm mekanizmayı bir bakıma durdurur. Böylece o zor anın gerilimini bedene hapseder. Çok geçmeden biz nefes alma kapasitemizin ancak \%20'sini kullanıyor olur böylece enerji kapasitemizi de \%20 ye çekmiş oluruz (Vas LSR, 2016).

Kaburga nefesi; Kaburga nefesi ciğerlerin sadece \%20'lik bölümünün kullanılmasına imkân tanır. Sadece uykuda 
oksijen ihtiyacının karşılanmasını sağlayabilir.

Diyafram nefesi; Alt veya karın solunumu da denilen bu nefes alma modeli ciğerlerin altında yapışık bulunan diyafram kasının aşağı ve yukarı hareketi ile belirlenir.

Bire bir buçuk oranında akciğerlerin genişlemesini ve hava dolmasını sağlar. Yeterlilik oluşturabildiğinde 2500-2700 cl arasında olan akciğer hacmi 5500-7000 cl ye kadar genişletilebilir.

Aslında dünyaya gelindiği an itibariyle yaşam diyafram nefesi alarak başlar. Bebeklerin sesinin bu kadar çok çıkabilmesinin, diyafram nefesiyle ilişkili olduğu düşünülmektedir.

Köprücük kemiği nefesi (clavicular solunum); Köprücük kemiğinin hareketi ile akciğerlerin yukarı doğru genişlemesini sağlayan daha çok şarkıcıların kullandığı yumuşak damak, farenks ve larenksin kullanılmasında kolaylık sağlayan bir tekniktir. Sığ bir nefes alma tekniğidir ve gögüsten alınan nefesin çoğu gerekli yerlere ulaşmaz ve maksimum eforla minimum fayda sağlar. Mesela astım hastaları göğüs nefesini kullanırlar (Kartal M, 2018). Bir araştırmada göğüs nefesinin vücudun savunma mekanizmasında görevli olan $\mathrm{T}$ lenfositlerin üretiminde elzem olan sitokin maddesini azalttığ 1 saptanmıştır. Ayrıca beyin, sinir ve kalp hastalıkları riskini arttıran homosistein adlı aminoasitin üst solunum yollarında $\operatorname{arttığı~belirtilmiştir~(Şinik~E,~2019).~}$

\subsection{Nefes Terapisinin Sağlığa Etkileri}

Uzun yıllar boyunca, kronik akciğer hastalığı olan bireylere sağlık profesyonellerinin yaklaşımı inaktivite, istirahat ve medikal tedavi ile sınırlı kalmıştır. Fakat yapılan son yapılan çalışmalar kronik solunum yolu hastalıklarında düzenli fiziksel aktiviteye ek olarak yapılan solunum egzersizinin de yaşanılan dispnenin azaltılmasına yardımcı olacağı bildirilmektedir (Özulus F, 2018). Hizlı nefes alıp verme davranışı, nefes hızının ve derinliğinin uyumsuz olduğu davranışsal hipokapniye neden olur. Bunun sonucu $\mathrm{pH}$ seviyesinde yükselme, ya da solunum yolu alkalozisi ile anlık ve uzun vadeli etkileri tetikler, şiddetlendirir ve/veya çok çeşitli duygusal (kaygı, öfke), bilişsel (odaklanma, öğrenme), davranışsal (toplum konuşması, test etme), fiziksel (ağrı, astım) değişimler ile sağlığı olumsuz yönde etkileyebilir. Düzenli yapılan solunum egzersizlerinin, diyafram kasını kuvvetlendirdiği, dispneyi azalttığı, akciğerlerin kapasitesini arttırdığı ve sekresyon hareketliliğini sağladığı belirtilmektedir (Özulus F, 2018). Araştırmacılar sadece on beş dakika derin nefes alarak günlük enerji ihtiyacının karşılanabileceğini keşfetmişlerdir. Ne yazık ki çoğu insan nefesin gücünü, bu yararları elde etmeyi sağlayacak biçimde doğru kullanmayı bilemediği için enerji potansiyelini sınırlı kullanmaktadır (Vas LSR, 2016). Hipertansiyon hastaları için geliştirilen Resperate isimli solunum rehberi görevi gören bir aletin klinik çalışmalarının tamamlanması üzerine yapılan bir derlemede; geçmişte meditasyonla ilişkili yavaş ve derin nefes ("tempolu nefes"), barorefleks duyarlılığını artırarak doğrudan antihipertansif etkiye sahip olduğu bildirilmiştir. ABD Gıda ve İlaç İdaresi onaylı bir cihaz olan RESPeRATE, solunum hızını yönlendiren yöntemle, hipertansiyon tedavisi için kolay, verimli, ucuz ve invaziv olmayan bir seçenek olarak sunulmuştur. Birçok çalışma, RESPeRATE cihazı eşliğinde ev ve ofis ortamında nefes egzersizi uygulandığında yüksek olan kan basıncında düşme gerçekleştiğini göstermiştir. (Cernes, R. \& Zimlichman, R. 2017).
Nefes alışverişimiz, tıpkı yediğimiz yemeğin kalitesi, türü ve miktarının hayatımızı etkilemesi, şekillendirmesi gibi oldukça önemli bir konudur. Nefes almayı sadece soluk alıp vermek zannetmek, ne bulursak yemeyi beslenmek zannetmeye benzer (Lewis D, 2015). Günümüzde insanlar mesleki ve / veya kişisel yaşamlarına etkilerinden dolayı nefes tekniklerini öğrenme girişimlerinde bulunmaktadır.

Voroshilov ve ark. (2017) yapmış olduğu bir çalışmada modifiye edilmiş bir Çigong solunum egzersizinin açlik duygusunu azaltıp azaltamayacağı incelenmiş çalışmada 28 erkek 32 kadın grup ile çalışılmış egzersizin aç karnına açlık hissini önemli ölçüde azaltabileceği ve hatta baskılayabileceğine dair güçlü kanıtlar sunduğu sonucuna varılmıştır.

Nefes egzersizlerin stres üzerindeki etkilerini inceleyen Örün D, (2019) 15 genç kadın gönüllü katılımıyla yaptığı çalışmada nefes koçu gözetiminde 45 dakikalık doğal ve bağlantılı bir nefes egzersizi uygulatıldığı, nefes egzersizi öncesinde ve egzersiz sonrasında kortizol ve epinefrin hormonları ile SOD ve katalaz enzimlerine bakıldığını ve sonuç olarak da stres faktörlerinin azaltılmasında bir rahatlama tekniği olarak nefes egzersizlerinin kullanılabileceği sonucuna varmıştır. Stresin etkilerinde birçok bileşen vardır bunlardan bir tanesi de hormonların seviyesidir. Nefes terapisinin yer aldığ 1 bu çalışmada epinefrin düzeylerinde anlamlı bir değişiklik olmaz iken kortizol seviyelerinde anlamlı bir düşüş kaydedilmiştir.

Xiao M. ve ark. (2017) yapmış olduğu araştırmada 40 katılımcı randomize kontrollü olarak ikiye ayrılmıştır. Dikkat ve odaklanma üzerine ön test-son test uygulanmış ve tükürük ile kortizol seviyeleri belirlenmiştir. 8 hafta boyunca 20 seanslık kontrollü diyafram nefes egzersizi yapması sağlanmış bu çalışmanın sonunda kortizol seviyeleri ve dikkat/odaklanma üzerine olumlu etkileri olduğu saptanmıştır.

Körük nefesi tekniğinin akciğer kapasitesi üzerinde etkilerini inceleyen araştırmacılar randomize kontrollü yaptıkları çalışmada 30 sağlıklı erkeği iki gruba ayırarak 1 . Gruba $15 \mathrm{dk}$ körük nefes tekniği uygulatılmış 2. Gruba ise 1 ay boyunca haftada 6 gün $15 \mathrm{dk}$ koşu yaptırılmış. Çalışmanın sonucunda

2. Gruptaki katılımcıların akciğer kapasitelerindeki artışın 1. Gruptaki katılımcılara göre daha az olduğu saptanmış. Pranayama'nın spora dahil edilmesinin, özellikle aerobik sporlara katılanlar ve yeterli oksijen alımını sağlamak için verimli akciğerlere ihtiyaç duyanlar için akciğerlerin ventilasyon işlevlerini artırarak sağlıklı bireylerin ve sporcuların verimliliğini artırabileceğini göstermektedir

(Budhi R. Et al.2019). Kim K. ve ark (2019) 45 yaşlı kadın ile yaptıkları randomize kontrollü çalışmada elastik bant ile yapılan egzersize nefes teknikleri eklendiğinde deneysel grup zorlu vital kapasitede (FVC), zorlu ekspiratuar hacim 1 sn'de (FEV 1) ve FEV 1 de önemli bir artış gösterdiği saptanmıştır.

Jayawardena ve ark. (2020) pranayama'nın faydalı sağlık etkileri hakkında sistematik bir inceleme yapmış olup bununla ilgili 18 çalışma seçilerek incelendiğinde Pranayama ile ilgili mevcut kanıtlar fizyolojik ve psikolojik faydalarının olduğu yararlı etkiler daha çok bronşiyal astım gibi solunum yolu hastalıkları olan hastalarda gözlendiği ayrıca kanser ve kardiyovasküler hastalığı olanlara da fayda sağladığ sonucuna varılmıştır. Esansiyel hipertansiyonda yavaş nefes almanın nabız değişkenleri ve arteriyel barorefleks duyarlılığı 
üzerindeki etkilerini araştırmak için 60 esansiyel hipertansiyonu olan ve 60 sağl1klı iki grup oluşturulmuş. Tüm katılımcılara dakikada 8 ve 16 kontrollü nefes çalışması

yaptırılmış, elektrokardiyogram, solunum ve kan basıncı sinyalleri aynı anda kaydedilmiş ayrıca, hipertansif hastalarda yavaş nefes almanın barorefleks duyarlılığını değiştirip değiştiremeyeceğini test edilmiştir. Dakikada 16 nefes ile karşılaştırıldığında yavaş nefes alma, kalp atış hızını ve kan basıncını düşürdüğü ve hipertansif kişilerde de yavaş nefes egzersizinin barorefleksleri düşürdüğü saptanmıştır (Li C, et al.2018).

Bir grup araştırmacı pranayama nefes tekniklerinin serebrovasküler hemodinamik üzerindeki etkilerini araştırmış, araştırmaya yoga ve pranayama eğitimi almış 15 sağlıklı gönüllü erkek dahil edilmiş ve pranayama nefes tekniklerinden olan körük nefes ve nefes tutma egzersizleri uygulatılmış bu egzersizler sırasında Transkraniyal Doppler takibi yapılmıştır. Araştırmanın sonucunda körük nefes

uygulanırken diyastol sonu hızda ve ortalama akış hızında düşüşler pulsatilite indeksinde önemli bir artış gözlenmiş nefes tutma egzersizi sırasında ise bu değerlerin tam zit etki gösterdiğini ve hastaların gereksinimlerine göre uygulamaya dahil edilebileceği sonucuna varılmıştır (L Nivethitha., et al

2017).

Pranayama nefes egzersizinin kronik obstrüktif akciğer hastalığı $(\mathrm{KOAH})$ olan bireylerin egzersiz toleransına etkisini araştıran bir grup araştırmacı randomize kontrollü pilot çalışmalarında 12 haftalık hastalara verdikleri pranayama nefes egzersizi eğitimi sonunda deney grubunda egzersiz toleransında 6 dakikalık yürüme mesafesinde gelişme olduğunun sonucuna ulaşmışlardır (David A K., et al.2017).

Ranil J. ve ark. (2020) yaptıkları sistematik derlemede 669 makale içerisinden 18 çalışma seçilmiş ve hepsi kontrollü çalışma olduğunu ve çalışmalar, bronşiyal astımlı hastalarda nabız hızı, sistolik kan basınc1 ve solunum fonksiyonu ölçümlerinde iyileşme ile kardiyorespiratuar fonksiyonlar üzerinde önemli bir etki olduğunu göstermiştir. Ayrıca, yaşam kalitesinin artmasıyla atakların sıklığında, şiddetinde ve ilaç ihtiyacında da azalma gözlenmiştir. Kronik obstrüktif akciğer hastalığı olan hastalarda semptom, aktivite ve etki skorlarının iyileştirildiği sonucuna ulaşılmıştır.

\subsection{Nefes Terapisinin Kadın Sağlığına Etkileri \\ KonusundaYapılan Çalışmalar}

Üreme çağındaki kadınlarda doğumu ağrısız ve kolay yapabilmek için çok fazla yöntem denenmiş olmasına rağmen tüm kadınlar tarafından tercih edilen ve uygulanan standart bir ağrı giderme yöntemi yoktur. Bu durum gebelerin; doğumda ağrıyı etkin şekilde yönetmelerine yardımcı olacak, doğuma katılmalarını engellemeyecek ve yan etkisi olmayan tamamlayıcı ve alternatif tedavilere (TAT) yönelmelerine neden olmuştur. Doğumda kullanılan nefes teknikleri, gebenin dikkatini ağrı anında değişik noktalara yöneltir, ağrı eşiğini yükseltir, gevşemesini sağlar, utero-plasental dolaşımı rahatlatır, ağrının algılanmasını azaltır (Yıldırım G. Şahin N. H. 2003). Doğum eyleminde nefes alma teknikleri güçlü bir aktivasyon oluşturarak serebral korteksin diğer bölgelerinde uterusta ağriya neden

olan stimülasyonları baskılar. Sonuçta sözlü uyarıların eylemde korku, rahatsızlık ve ağrının azaltılmasında bir yol olduğunu ifade ederek bir yöntemin doğmasını sağlamıştır (Coşar F, Demirci N,2012). Yüksel H. ve ark. (2017) yaptı̆̆ 1 randomize kontrollü bir çalışmada doğum eyleminin ikinci

evresinde gebe kadınlar için nefes egzersizlerinin maternal ağr1, doğum süresi ve nabız, aktivite ve solunum (APGAR) puanları üzerinde yararlı etkileri olup olmadığ incelenmiş ve yalnızca 1 seans nefes terapisi uygulanmıştır. Çalışmanın sonucunda gebe kadınlarda derin soluma ve soluma ile

solunum egzersizleri, doğum sancısı algısını azaltmada ve doğumun ikinci aşamasının süresini kısaltmada etkili olduğu saptanmıştır. Yeşildağ B. Gölbaşı Z. (2018) Doğum Ağrısının Yönetiminde Nonfarmakolojik Yöntemlerin Etkinliğini Değerlendiren Lisansüstü Tez Çalışmalarının İncelenmesi çalışmasında da doğum eyleminde uygulanan nefes egzersizleri eğitiminin doğum ağrısı algısını azaltmada ve eylemin süresini kısaltmada etkili olduğu belirlenmiştir.

Demirbilek H. ve ark. (2019) araştırma konusu olan doğru nefes alarak diyaliz kaygısının azaltılması sağlanabilir mi? sorusuna çalışmanın sonuçları hastaların diyaliz seansı sırasında, anlık ve sürekli kaygılarını düşürmede doğru nefes alarak gevşeme terapisi uygulanmasının uygun olabileceği ve önerilebileceği yönündeydi.

Çiçek ve ark. (2017) yapmış olduğu bir çalışmada nefes alma teknikleri eğitiminin hamile kadınların anksiyete düzeyleri ve doğum süresine etkileri incelendiğinde toplamda 70 gebe kadın katılım sağlamış ve 35 kadına doğumun latent fazında nefes terapisi uygulanmış olup gebelerin anksiyete düzeyleri üç kez ölçülmüştür. Çalışmadan çıkan sonuca göre nefes terapisinin doğum sırasında anksiyeteyi azaltmada etkili olduğu kanıtlanmıştır. Kusmiran ve ark. (2014) sezaryen doğum yapmış 21 kadınla yaptıkları çalışmada gevşeme ve derin nefes egzersizi uygulamasının ardından ağrı yanıtı

puanında anlamlı bir azalma olduğunu saptamıştır. Ölçer ve Oskay'ın (2015) yaptıkları çalışmada yüksek riskli gebelikte stresle baş etme yöntemleri arasında solunum egzersizleri hipertansiyon, yorgunluk ve anksiyetenin azaltılmasında da yararlılduğuna, çeşitli solunum tekniklerinin (göğüs solunumu, karın solunumu gibi) varlığına ve annenin gereksinimine göre uygulanabileceğine, solunum egzersizlerinin ise gevşeme ile birlikte kullanıldığında

daha etkili olacağına değinilmiştir.

Nefes terapisinin ağrı yönetimi ile ilgili yapılan bir başka çalışmada bu kez 56 öğrencinin dismenoreyi azaltmada nefes terapisinin etkisi incelenmiş ağrı skalasındaki ortalamanın düştüğü saptanmıştır (Azizah, N., \& Nisak, A. Z. 2015). Kronik bel ve sırt ağrısı olan hastalarda yapılmış bir çalışmada solunum sırasında ağrının sebep olduğu kısıtlı torasik hareketlerden ötürü nefes alma kapasitelerinin düştüğü belirtilmiş ve randomize kontrollü 62 kişi üzerinde solunum egzersizi ve bel ağrısına özgü tedavileri uygulanmış, 2 haftalık uygulama egzersizlerinden sonra ağrı ve hareket kısıtlılığında anlamlı derecede iyileşme olduğu sonucuna varılmıştır. (Babina R, et al.2016).

Derin ve yavaş nefes almanın ağrı algısı ve ruh hali üzerinde etkilerini araştıran Busch V.ve ark. (2012) solunum egzersiz seansları düzenlenen 16 katılımciya derin solunum sonrasında yavaş solunum teknikleri uygulatılmış. Seanslardan önce ve sonra soğuk-sıcak uyaranlar için termal algılama, ağrı eşikleri 
ve duygu-durum değişkenlerinin profili incelenmiştir. İki tekniğinde rahatlama ve ağrı algısının düşmesinde olumlu etkileri olduğu saptanmıştır.

Mulhaeriah ve ark. (2018) gevşeme solunum egzersizinin kemoterapi alan jinekolojik kanser hastalarında yorgunluk üzerine etkisini incelemiş ve çalışmanın sonunda yorgunluk skorlarında anlamlı bir azalma tespit edilmiştir.

Baskaran (2014) 260 menopoz döneminde olan kadın grubunun randomize olarak iki gruba ayırıp 130 kadına yoga ile birlikte nefes terapisi uygulamıştır. Bu çalışmanın sonunda yaşam kalitelerinde artış olduğu gözlenmiştir. Yine menopozal dönemdeki kadınlarla yapılan başka bir çalışmada menopozal sıcak basmaların sıklığını ve şiddetini azaltmak için cihaz güdümlü yavaş solunum etkinliğini değerlendirmek amacıyla 123 kadına rehber solunum cihazıyla nefes terapisi uygulanmıştır. Bu çalışmanın sonucunda menopoz döneminde yaşanan sıcak basmasının sıklık ve şiddet yönünden azaldığı bildirilmiştir (Alison H. J, et al. 2016).

\section{Kaynaklar}

Acar N. , (2016). Nefes, kullanımı ve şan eğitimi, Ulakbilge, 4, 231-246.

Aktaş B., (2017) Hemşirelik Öğrencilerinin Bütüncül Tamamlayıcı ve Alternatif Tıbba Karşı Tutumları G.O.P. Taksim E.A.H. JAREN 2017;3(2):55-59

Alison Huang J., Sara P. , Michael S. , Eric V. , Deborah G., (2016) Device - Guided Slow- Paced Respiration for Menopausal Hot Flushes: A Randomized Controlled Trial. Obstet Gynecol. Author manuscript ; available in PMC 2016 May $1 . \quad$ DOI: 10.1097/AOG.0000000000000821

Azizah, N., \& Nisak, A. Z. (2015). Teknik Relaksasi Nafas Dalaman Dan Terapi Musik Sebagai Upaya Penurunan Intesitas Nyeri Haid (DYSMENORRHEA) The 2nd University Research Coloquium 2015 ISSN 24079189

Babina R. , Mohanty PP. , Pattnaik M., (2016) Effect of thoracic mobilization on respiratory parameters in chronic non-specific low back pain : A randomized controlled trial. J Back Musculoskelet Rehabil. 2016 Feb 19;29(3):587-95. doi: 10.3233/BMR-160679.

Baljon, K. J. , Romli, M., H.Ismail. , A. H. Khuan L., \& Chew, B. H., (2020). Effectiveness of breathing exercises, foot reflexology and back massage (BRM) on labour pain, anxiety, duration, satisfaction, stress hormones and newborn outcomes among primigravidae during the first stage of labour in Saudi Arabia: a study protocol for a randomised controlled trial. BMJ open, 10(6), e033844. https://doi.org/10.1136/bmjopen-2019-033844

Baskaran J., and Arulappan J., (2014) Complementary health approach to quality of life in menopausal women: a community-based interventional study.Clin Interv Aging. 2014; 9: 1913-1921.Çevrimiçi yayın yapan 2014 Nov 7. doi: 10.2147 / CIA.S70064

Budhi R., B.Payghan S., and Deepeshwar S., (2019) Changes in Lung Function Measures Following Bhastrika Pranayama (Bellows Breath) and Running in Healthy Individuals. Int J

\section{Sonuç ve Öneriler}

Yapılan çalışmalar nefes terapisinin genel sağlık ve kadın sağlığı üzerine olumlu etkilerinin olduğunu göstermektedir. İnsana yardım etmeyi temel alan hemşirelik mesleğinin sağlı̆̆a holistik bir yaklaşımla bilimin 1şı̆̆ında ilk olarak sağlığı koruma ve geliştirme adına Tamamlayıcı ve Alternatif Tedavi yöntemlerinden olan nefes terapisi konusunda daha fazla araştırmaya ihtiyaç duyulmaktadır.

Unutmayalım ki sağlık profesyonellerinin bu gibi yöntemleri araştırmalarda ve klinik uygulama alanlarında yer almaması gelecek dönemlerde bu uygulamaların faydasının aksine zararı olabilir yada hiç kullanılmayarak atıl durumda kalabilir. Nefes terapisi yönteminin yararlarının kesin olduğunu ifade etmek ve nefes terapisinin oluşturduğu terapötik

faydanın altında yatan mekanizmaları açıklayabilmek için bu konuda daha fazla randomize kontrollü çalışmanın yapılmasına ihtiyaç vardır.

Yoga. 2019 Sep - Dec; 12(3): 233-239. doi: 10.4103/ijoy.IJOY_43_18

Busch V., Walter M., Uwe K., Joachim H., Göran H., Peter E., (2012) The effect of deep and slow breathing on pain perception, autonomic activity, and mood processing-an experimental 327 study. Eichhammer P.Pain Med. 2012 Feb; 13(2):215-28. DOI: 10.1111/j.1526- 328 4637.2011.01243.x

Cernes, R., \& Zimlichman, R., (2017). Role of paced breathing for treatment of hypertension. Current hypertension reports, 19(6), 45. doi: 10.1007/s11906017-0742-1.

Cicek S., Basar F., (2017) The effects of breathing techniques training on the duration of labor and anxiety levels of pregnant women. Complement Ther Clin Pract. 2017 Nov;29:213-219. doi: 10.1016/j.ctcp.2017.10.006.

Coşar F., Demirci N., (2012) Lamaze Felsefesine Dayalı Doğuma Hazırlık Eğitiminin Doğum Algısı ve Doğuma Uyum Sürecine Etkisi. DergiPark Süleyman Demirel Üniversitesi Sağlık Bilimleri Dergisi Arşiv Cilt 3, Sayı 1Y11 2012, Cilt 3 , Say1 1, Sayfalar $18-30$

David A K., Kalpalatha K G., Joan L., Stephanie M., Melissa Bir B., Joan S., Michael D., Heidi Pecott-G., Ali M., Catherine LaRock-McM., Penney W., Martha C W. , Nicola A H.,(2017)

Effect of Yoga Breathing (Pranayama) on Exercise Tolerance in Patients with Chronic Obstructive Pulmonary Disease: A Randomized, Controlled Trial 2017 Sep;23(9):696704. doi: 10.1089/acm.2017.0102.

Demirağ S., (2019) Geleneksel ve Tamamlayıcı Tıp Uygulamaları Hipokrat Yayıncılık 2019 sf. 13-27, 28

Demirbilek H., Nalçacı S. O., Taş D., Akgüç Tanay E., Parmaksız E., Külah E., (2019) Doğru Nefes Alarak, Diyaliz Kaygısını Azaltabilir miyiz? Nefroloji Hemşireliği Dergisi 2019;14 (3):97-102 Gündoğdu F., (2019) Radyoterapi alan meme kanseri kadınlarda iki farklı yöntemle uygulanan nefes egzersizinin yorgunluk ve uyku kalitesi üzerine etkisi: Randomize kontrollü çalışma 2019 Doktora Tezi Ankara Yıldırım Beyazıt Üniversitesi Sağlık Bilimleri Enstitüsü Hemşirelik 


\section{Anabilim Dalı}

https://www.resmigazete.gov.tr/eskiler/2014/10/201410273.htm Erişim: 08.09.2020

Jayawardena R., Priyanga R., Himansa R., Nishadi G., Dilshani D., and Anoop M., (2020) Exploring the Therapeutic Benefits of Pranayama (Yogic Breathing): A Systematic Review. Int J Yoga. 2020 Mayıs-Ağustos; 13 (2): 99-110. Çevrimiçi yayın tarihi 2020 1. Mayıs : 10.4103 / doi: 10.4103/ijoy.IJOY_37_19

Jerath R., Edry JW., Barnes VA., Jerath V. ,( 2006) . Physiology of long pranayamic breathing: Neural respiratory elements may provide a mechanism that explains how slow deep breathing shifts the autonomic nervous system. Medical Hypothesis, 67, 566-571. DOI: 10.1016/j.mehy.2006.02.042

Kartal M., (2018) Nefes Terapisi, Ray Yayıncılık 4. Bask1 2018 sf. 17 - 203

Kim K., Han J.W., Kim M.Y., (2019) Effects of elastic band resistance exercises with breathing techniques on pulmonary function in female seniors. $\mathbf{J}$ Egzersiz Rehabil. 2019 Haziran; 15 (3) : 419-423. Çevrimiçi yayın tarihi 2019 Haz 30. doi: 10.12965 / jer.1938070.035

Kusmiran E., Manalu L.O., (2014) Deep Breath Relaxationandh Autogenic Relaxationto The Response Scaleof Painon Post Caesarean Section Woman. Nursing Journal Of Education And Clinic (INJEC) = http://dx.doi.org/10.24990/injec.v1i1.50

Lewis D., (2015). Nefes Almayı Bilmek-Adım Adım Nefes Teknikleri, Şira yayınları, 2. Baskı İstanbul sf. 50-51-52.

Li C. Chang Q. Qinghua C., Jia Z., Wenshu C., (2018) Effects of slow breathing rate on heart rate variability and arterial baroreflex sensitivity in essential hypertension Medicine (Baltimore). 2018 May; 97(18): e0639. Published online 2018 May 4. doi: 10.1097/MD.0000000000010639

Mulhaeriah A. Yati A., Engkus Kusdinar A., Moh Syafar S., (2018) Effectiveness of Relaxation Breathing Exercise on fatigue in gynecological cancer patients undergoing chemotherapy. Int J Nurs Sci. 2018 Oct 10; 5(4): 331-335. Published online 2018 Sep 18. doi: 10.1016/j.ijnss.2018.09.004

NivethithaL., Bir M., NK M., Lokesh B., Vijay K S., (2017) Cerebrovascular hemodynamics during pranayama techniques. J Neurosci Rural Pract. 2017 Jan-Mar; 8(1): 60-63. doi: 10.4103/0976-3147.193532

Novotny S., Kravitz L., (2013). The science of breating, https://alchemicalbody.wordpress.com/2013/05/21/thescience-of-breathing/ Erişim 07.09.2020

Ölçer Z., Oskay Ü., (2015) Yüksek Riskli Gebelerin Yaşadığı Stresörler ve Stresle Baş Etme Yöntemleri Hemşirelikte Eğitim ve Araştırma Dergisi 2015;12 (2): 85-92

Örün D., (2019) Nefes Egzersizinin Stres Hormonlarına Etkisi Selçuk Üniversitesi Sağlık Bilimleri Enstitüsü Yüksek Lisans Tezi

Özulus F., (2018) Astım ve Egzersiz Balıkesir Sağlık Bilimleri Dergisi. Cilt:5 Say1:1 Nisan 2016

PEKSOY, S., DEMIRHAN, İ., KAPLAN, S., ŞAHIN, S., \&
DÜZGÜN, A. A. Tamamlayıcı ve Alternatif Tedavinin Jinekolojik Kanserlerde Kullanımı. Türkiye Sağlık Bilimleri ve Araştırmaları Dergisi, 1(1), 36

Peter M., Litchfield., (2006) Breathing is behavior, a unique behavior that regulates body chemistry, pH. May 2006 Good Breathing, Bad Breathing

Ranil J., Priyanga R., Himansa R., Nishadi G., Dilshani D., Anoop M., (2020) Exploring the Therapeutic Benefits of Pranayama (Yogic Breathing): A Systematic Review May-Aug 2020;13(2):99-110. doi:10.4103/ijoy.IJOY_37_19.

Ritz T., Roth WT., ( 2003). Behavioral intervention in asthma. Behavior Modification, 27, 710- 730. doi: 10.1177/0145445503256323.

Sandoz T., (2010) Alternatif Tip Tarihi Dost kitap evi ceviri: Çağrı Eroğlu Ekim 2010, 239

Şinik E., (2019) Nefeste Saklı Hayat Libros Yayınları 9. Basım 2019 sf. 53-133

Vas LSR., (2016). İyileştiren Nefes Nefesin İyileştirici , Huzur Verici ve Aydınlatıcı Gücünü Kullanmak, Akaşa yayınları 2.Bask1 İstanbul sf. 9-107

Voroshilov A.P., Alex A V., Zhixin W., Elena V M., (2017) Modified Qigong Breathing Exercise for Reducing the Sense of Hunger on an Empty Stomach.J Evid Based Complementary Altern Med. 4062017 Oct; 22(4): 687695. Published online 2017 May 12. doi: 407 10.1177/2156587217707143

Xiao M. Zi-Qi Y. Yue, Zhu-Qing G., Hong Z., Nai-Yue D., Yu-Tong S., Gao-Xia W., You-Fa L., (2017) The Effect of Diaphragmatic Breathing on Attention, Negative Affect and Stress in Healthy Adults Front Psychol. 2017; 8: 874. Published online 2017 Jun 6. doi: 10.3389/fpsyg.2017.00874

Yeşildağ B., Gölbaşı Z., (2018) Doğum Ağrısının Yönetiminde Nonfarmakolojik Yöntemlerin Etkinliğini Değerlendiren Lisansüstü Tez Çalışmalarının İncelenmesi Düzce Üniversitesi Sağlık Bilimleri Enstitüsü Dergisi Arşiv Cilt 8, Sayı 3 Y11 2018, Cilt 8 , Say1 3, Sayfalar 104-111

Yıldırım G., Hotun Şahin N., Doğum Ağrısının Kontrolünde Hemşirelik Yaklaşımı C. Ü. Hemşirelik Yüksek Okulu Dergisi 2003, 7 (1)

Yuksel H., Cayir Y., Kosan Z., Tastan K., (2017) Effectiveness of breathing exercises during the second stage of labor on labor pain and duration: a randomized controlled trial. J Integr Med. 2017 Nov;15(6):456-461. DOI: 10.1016/S2095-4964(17)60368-6

Yüksel H., (2016)Normal Doğumda Nefes Egzersizlerinin Doğum Travayına Etkisi Uzmanlık Tezi Atatürk Üniversitesi Tıp Fakültesi Erzurum. 